RU Сложные существительные подчинительного типа в венгерском языке

\author{
Арискина Т. П.
}

\begin{abstract}
Аннотация. Цель исследования - выявить наиболее продуктивные модели образования сложных существительных подчинительного типа в венгерском языке. Основное внимание уделяется рассмотрению разных частей речи в качестве первого компонента. Научная новизна работы заключается в подробном анализе сложных существительных подчинительного типа в венгерском языке на материале словаря “Magyar-orosz szótár = Венгерско-русский словарь". В результате установлено, что первым компонентом может быть любая часть речи, а вторым выступает существительное, которое и определяет принадлежность сложных слов к данной части речи. Приведенные примеры подтверждают, что образование сложных существительных на основе подчинительной связи - продуктивный способ словообразования.
\end{abstract}

\title{
EN Compound Nouns of Subordinate Type in the Hungarian Language
}

\author{
Ariskina T. P.
}

\begin{abstract}
The paper aims to identify the most productive word-formation models for compound nouns of subordinate type in the Hungarian language. The main focus of attention lies in the consideration of differrent parts of speech as the first component. The scientific originality of the research consists in the thorough analysis of compound nouns of subordinate type in the Hungarian language on the material of the dictionary "Magyar-orosz szótár = Hungarian-Russian Dictionary". As a result, it has been revealed that any part of speech can be the first component, while the second component is presented by a noun, which determines the belonging of compound words to this part of speech. The examples provided prove that the formation of compound nouns based on the subordinate relationship is a productive way of word-formation.
\end{abstract}

\section{Введение}

Сложные имена существительные в венгерском языке К. Е. Майтинская (1959) делит на четыре группы:

1) сложные слова подчинительного типа; 2) сложные слова сочинительного типа (парные существительные); 3) сложенные путем стяжения членов целого предложения; 4) сложносокращенные существительные (с. 151).

Из перечисленных групп самую большую составляют композиты подчинительного типа, а самую маленькую - сложенные путем стяжения членов целого предложения.

Актуальность темы исследования определяется тем, что имя существительное занимает центральное место в грамматической системе языка. В связи с изменениями в науке многие словообразовательные процессы могут быть рассмотрены с новых позиций, поэтому их изучение актуально и в настоящее время.

Предметом настоящего исследования являются сложные существительные подчинительного типа в венгерском языке. Для достижения цели исследования необходимо решить ряд задач: выявить основные группы с разными частями речи в качестве первого компонента; определить продуктивность словообразовательных моделей.

При написании статьи использовались методы индукции, описательный и компонентного анализа. Также применялись методы первичной обработки, систематизации исследуемого материала, сплошной выборки.

Теоретическая база исследования: практически во всех научных грамматиках разных языков имеются сведения о словосложении, дается классификация композитов по какому-либо принципу. Например, в академической грамматике русского языка 1960 г. (Грамматика русского языка, 1960) словосложение исследуется достаточно подробно, представлена характеристика таких образований по лексико-грамматическому основанию. В грамматике 1970 г. (Грамматика современного русского литературного языка, 1970) словосложение подразделяется на два типа: 1) сложение с сочинительным отношением основ; 2) сложение с подчинительным отношением основ. Классификация композитов здесь осуществлена с учетом опорного компонента сложного слова. Е. А. Василевская (1962) анализирует две большие группы: 1) композиты без соединительной 
гласной; 2) композиты с соединительной гласной. Однако подобный подход не дает представлений о сложной структуре формирования сложных слов, не позволяет раскрыть взаимоотношения их компонентов и лексико-грамматические связи.

Сложные существительные подчинительного типа в венгерском языке описаны в учебниках и грамматиках (Балашша, 1951; Науменко-Папп, 1982; Jászó, 2007; Hegedűs, 2004; Kiss, Kiefer, Siptár, 2003; Korchmáros Valéria, 2006; Magyar grammatika, 2017). Наиболее полный анализ грамматического словообразования прилагательных венгерского языка осуществила К. Е. Майтинская (1959).

Материалом для исследования послужил словарь “Magyar-orosz szótár = Венгерско-русский словарь”, составленный L. Gáldi и P. Uzonyi (Gáldi, Uzonyi, 2000). Для анализа были выбраны сложные имена существительные, образованные на основе подчинительной связи в венгерском языке.

Практическая значимость исследования заключается в том, что результаты исследования могут быть использованы в обобщающих трудах по словообразованию, в лекционных курсах по сравнительному языкознанию, а также современному венгерскому языку.

\section{Основная часть}

Основное место среди сложных существительных венгерского языка, бесспорно, принадлежит сложным существительным подчинительного типа (детерминативным (определительным) композитам). Обогащение словарного состава исследуемого языка сложными существительными происходит главным образом за счет именно данного типа словосложения. Он является наиболее продуктивным на протяжении всей истории развития рассматриваемого языка, а также в настоящее время.

В состав композитов подчинительного типа входят разные части речи, при этом первым компонентом может быть любая часть речи, а вторым обычно выступает существительное, которое и определяет принадлежность сложных слов к данной части речи. В зависимости от того, какая часть речи выступает в качестве первого компонента, детерминативные композиты в венгерском языке делятся на группы с первым компонентом существительным, прилагательным, числительным, местоимением, причастием и наречием. Рассмотрим их подробнее.

\section{1. Сложные существительные, первый компонент которых - существительное}

В венгерском языке способ образования сложных слов путем сложения двух основ, представляющих собой существительные, является самым продуктивным. Наиболее часто встречаются детерминативные композиты, первый компонент которых имеет абсолютную форму (номинатив единственного числа без притяжательного окончания).

Сложные существительные, первый компонент которых - существительное, группируются по следующим словообразовательным типам:

а) второй компонент обозначает предмет, который составляет часть предмета, выраженного первым компонентом, например: ágyúcső ‘дуло пушки’ < ágyú ‘пушка' + cső ‘дуло’; almahéj ‘кожура яблока’ < alma 'яблоко’ + héj ‘кожура'; fatörzs ‘ствол дерева’ < fa 'дерево’ + törzs ‘ствол’; házhomlokzat ‘фасад дома' < ház ‘дом’ + homlokzat ‘фасад’. Этот словообразовательный тип является неограниченно продуктивным. Любая часть предмета может быть названа указанным путем (за исключением тех, которые уже имеют какое-либо общераспространенное название другого типа);

б) второй компонент обозначает предмет, явление, отвлечённое понятие, которые относятся к другому предмету, выраженному первым компонентом, например: ágyúszó ‘канонада' < ágyú ‘пушка’ + szó ‘слово, речь’; országhatár 'государственная граница' < ország 'страна' + határ 'граница’; Országház ‘парламент, здание парламента’ < ország ‘страна' + ház ‘дом’; rózsaillat ‘благоухание роз’ < rózsa 'роза’ + illat ‘аромат, благоухание’. Данный тип является также очень продуктивным;

в) второй компонент обозначает предмет, который предназначен для другого предмета, обозначенного первым компонентом, например: épületfa 'строительный лесоматериал' < épület 'здание' + fa 'дерево’; gázálarc 'противогаз' < gáz 'газ' + álarc 'маска'; gépállomás 'машинно-тракторная станция' < gép 'машина' + állomás 'станция’; tehénistálló ‘коровник’ < tehén ‘корова’ + istálló ‘хлев’. Сюда же относятся композиты, в которых второй компонент выражает место, где производится или продается другой предмет, обозначенный первым компонентом (Майтинская, 1959, с. 159), например: acélöntöde ‘сталелитейный цех’ < acél ‘сталь’ + öntöde ‘литейный цех’; áruház 'универмаг’ < áru 'товар, изделие’ + ház ‘дом’; cipöüzlet ‘обувной магазин’ < cipő ‘обувь' + üzlet ‘магазин’; gépgyár ‘машиностроительный завод’ < gép 'машина' + gyár ‘завод, фабрика’; könyvkereskedés ‘книжный магазин’ < könyv ‘книга’ + kereskedés ‘магазин’; téglagyár ‘кирпичный завод’ < tégla ‘кирпич’ + gyár ‘завод, фабрика’;

г) второй компонент обозначает возраст, пол, положение (в производстве) лица, которое имеет какуюлибо профессию, обозначенную первым компонентом, например: doktornő ‘доктор' < doktor 'доктор' + nö 'женщина’; munkásleány ‘девушка-работница' < munkás ‘рабочий’ + leány ‘девушка’; munkásnő ‘работница’ < munkás 'рабочий’ + nő ‘женщина'; pincérleány ‘подавальщица' < pincér ‘официант’ + leány ‘девушка’; tanárnő ‘преподавательница' < tanár 'преподаватель’ + пö 'женщина'. По этим моделям могут быть образованы и другие слова. Данные композиты не могут быть заменимы словосочетаниями;

д) первый компонент выражает пол животного, обозначенного вторым компонентом, например: hímfarkas ‘волк' < hím 'самец' + farkas ‘волк'; hímoroszlán 'лев’ < hím 'самец' + oroszlán ‘лев’; nöstényjaguár 'самка ягуаpa’ < nöstény 'самка' + jaguar 'ягуар’. Продуктивность данного типа ограничена только тем, что у некоторых 
животных пол выражается разными словами, например: tyúk ‘курица’; kakas ‘петух’; tehén 'корова’; bika ‘бык’; üszó ‘телка’; tinó ‘бычок’. Большинство же названий животных не выражает пола, например: szamár ‘осел’; tigris ‘тигр’ и др., следовательно, от них свободно образуются слова типа nösténytigris ‘тигрица' < nöstény 'самка' + tigris 'тигр';

е) первый компонент обозначает материал, из которого сделан или состоит предмет, названный вторым компонентом, например: aranyfog ‘золотой зуб’ < arany 'золото’ + fog 'зуб’; aranygyürü 'золотое кольцо' < агапу ‘золото’ + gyürü ‘кольцо’; bádogkanna 'жестяной бидон’ < bádog 'жесть' + kanna ‘бидон’; falapát 'деревянная лопата' < fa 'дерево' + lapát 'лопата'; gyöngyfüzér 'жемчужные бусы' < gyöngy 'жемчуг' + füzér 'связка, венок'; téglaház ‘кирпичный дом’ < tégla ‘кирпич’ + ház ‘дом’. Указанный тип композитов очень продуктивный.

В венгерском языке много детерминативных композитов, в которых первый компонент указывает не на материал, из которого сделан или состоит предмет, обозначенный вторым компонентом, а на то, чем снабжен предмет, названный вторым компонентом (Майтинская, 1959, с. 160), например: gépfegyver 'пулемет' < gép 'машина' + fegyver 'оружие'; gépkocsi ‘автомобиль' < gép 'машина' + kocsi ‘повозка'; motorcsónak ‘моторная лодка' < motor 'мотор' + csónak 'лодка';

ж) в композитах выражаются трудноуловимые отношения предметов или понятий, обозначенных компонентами, но внутри этой группы обнаруживаются модели, которые являются продуктивными. Среди них выделяются следующие существительные:

- сложные слова со вторым компонентом -társ ‘товарищ’, например: bajtárs ‘боевой товарищ’ < baj ‘беда, неприятность' + társ ‘товарищ’; iskolatárs 'школьный товарищ' < iskola 'школа' + társ ‘товарищ’; kartárs ‘коллега' < kar 'персонал, личный состав' + társ 'товарищ’; kortárs ‘современник' < kor 'эпоха, период’ + társ 'товарищ'; szaktárs 'товарищ по профессии' < szak 'специальность' + társ 'товарищ';

- названия отраслей наук со вторым компонентом -tan 'наука', например: élettan 'биология’ < élet 'жизнь' + -tan 'наука'; földtan 'геология’ < föld 'земля’ + -tan 'наука'; számtan 'арифметика' < szám 'число’ + -tan 'наука'; vegytan 'химия’ < vegy 'химический’ + -tan 'наука';

- сложные слова со вторым компонентом -ipar 'промышленность', например: cipóipar 'обувная промышленность' < сіро̆ 'обувь' + ipar 'промышленность'; gépipar 'машиностроительная промышленность' < gép 'машина' + ipar 'промышленность'; vasipar 'металлургическая промышленность' < vas 'железо' + ipar 'промышленность’;

- наименование министров и министерств со вторым компонентом -miniszter ‘министр’ и -minisztérium 'министерство', например: hadügyminiszter 'военный министр' < hadügy 'военное дело’ + miniszter 'министр'; hadügyminisztérium ‘военное министерство’ < hadügy ‘военное дело’ + minisztérium ‘министерство’; külügyminiszter ‘министр иностранных дел’ < külügy ‘иностранные дела' + miniszter 'министр’; külügyminisztérium 'министерство иностранных дел' < külügy ‘иностранные дела' + minisztérium 'министерство’;

- название чего-либо неудачного, неприятного с первым компонентом -bal 'левая сторона', например: baleset 'несчастный случай’ < bal 'левая сторона' + eset 'случай’; balhit 'заблуждение' < bal 'левая сторона' + hit 'вера, убеждение'; balsejtelem 'дурное предчувствие' < bal 'левая сторона' + sejtelem 'предчувствие’; balsiker 'неудача, неуспех, провал' < bal 'левая сторона' + siker 'успех, удача';

3) во многих существительных вторым компонентом выступает слово, обозначающее действие, процесс. Большинство из них составляют композиты, у которых первый компонент, являясь притяжательным определением, в то же время обозначает объект выраженного во втором компоненте действия, например: adófizetés 'уплата налога' < adó 'налог' + fizetés 'плата'; erdökitermelés 'лесозаготовки' < erdö 'лес' + kitermelés ‘заготовка'; földmüvelés 'земледелие' < föld 'земля’ + müvelés 'возделывание, обработка'; hazaszeretet 'любовь к родине' < haza 'родина, отечество' + szeretet 'любовь'. Тип продуктивный;

и) меньше таких композитов, в которых первый компонент, являясь притяжательным определением, в то же время выражает субъект действия, обозначенного вторым компонентом, например: bányaomlás 'обвал в шахте' < bánya 'шахта' + omlás ‘обвал’; égzengés ‘гром’ < ég ‘небо’ + zengés ‘звучание'; hóesés ‘снегопад’ < hó ‘снег’ + esés ‘падение’; sáskajárás ‘нашествие саранчи’ < sáska ‘саранча’ + járás ‘нашествие’. Тип малопродуктивный;

к) ещё реже встречаются сложные существительные, в которых первый компонент обозначает косвенный объект действия, выраженного вторым компонентом, например: balesetbiztosítás 'страхование от несчастных случаев’ < baleset 'несчастный случай’ + biztosítás ‘страхование’; gázmentesítés ‘дегазация’ < gáz 'газ’ + mentesítés 'предотвращение'.

\section{2. Сложные существительные, первый компонент которых - прилагательное}

В этой группе композитов выделяются следующие словообразовательные типы:

а) первым компонентом является качественное прилагательное, которое выражает большей частью сорт, вид какого-либо предмета (растения, продукта и т.д.), указывая на одно из его свойств, или уточняет какоелибо лицо, общее понятие, например: édespaprika 'болгарский перец' < édes 'сладкий' + paprika 'перец'; fiatalember 'неженатый молодой человек’ < fiatal 'молодой’ + ember 'человек'; nehézipar 'тяжелая промышленность' < пеhéz ‘тяжелый’ + ipar 'промышленность'; sárgaborsó ‘горох’ < sárga ‘желтый’ + borsó 'горох’; savanyúvíz 'минеральная вода кислого вкуса' < savanyú ‘кислый’ + víz ‘вода'; vörösbor ‘красное вино' < vörös ‘красный’ + bor ‘вино'; zöldbab ‘стручковая фасоль' < zöld 'зеленый’ + bab ‘фасоль, боб’;

б) первым компонентом является относительное прилагательное на -s. Некоторые из таких прилагательных показывают, чем снабжен предмет, обозначаемый вторым компонентом, например: almásrétes ‘слоеный 
пирог с яблоками' < almás ‘с яблоками' + rétes 'рулет из слоеного теста’; halastó 'садок’ < halas ‘c рыбой’ + tó ‘озеро’. Тип продуктивный. Другая часть указанных прилагательных показывает назначение предмета, например: fáskamra 'дровяной сарай’ < fás 'с дровами' + kamra 'сарай’; levesestál 'миска для супа' < leveses 'с супом’ + tál ‘миска’; vízespohár ‘стакан’ < vízes ‘c водой’ + pohár ‘стакан’. Тип продуктивный.

\section{3. Сложные существительные, первый компонент которых - числительное}

Детерминативных композитов, первый компонент которых - числительное, в венгерском языке мало. Среди них выделяются:

a) сложные существительные, у которых первым компонентом выступают количественные числительные, например: hatszög 'шестиугольник' < hat 'шесть' + szög 'угол’; hétszög 'семиугольник' < hét 'семь' + szög 'угол'; négyszög ‘четырехугольник' < négy ‘четыре’ + szög ‘угол'; ötszög ‘пятиугольник' < öt 'пять' + szög ‘угол’. Эти термины созданы по образцу иностранных слов, так как «венгерскому языку не свойственен такой тип словосложения» (Майтинская, 1959, с. 157);

б) композиты, у которых первым компонентом выступают порядковые или дробные числительные (у порядковых суффикс -ik выпадает), например: harmadrész 'третья часть' < harmadik 'третья' + rész 'часть'; másodpéldány ‘второй экземпляр’ < második ‘второй’ + példány ‘экземпляр’; másodperc ‘секунда’ < második ‘вторая’ + perc 'минута'; negyedrész ‘четвертая часть' < negyedik 'четвертая’ + rész 'часть'. Продуктивно образуются лишь существительные по типу harmadrész 'третья часть'.

\section{4. Сложные существительные, первый компонент которых - местоимение}

Таких сложных слов в венгерском языке немного, например: magatartás 'поведение' < maga 'своя' + tartás 'манера держать себя'; önbírálat 'самокритика' < ön 'само' + bírálat 'критика'; öncél 'самоцель' < ön 'само’ + cél 'цель’; önelemzés ‘самоанализ’ < ön 'само’ + elemzés 'анализ’; önéletrajz ‘автобиография’ < ön ‘само’ + életrajz ‘биография’; önérzet 'самолюбие' < ön 'само' + érzet 'ощущение, чувство’; öndicséret 'самовосхваление’ < ön 'само’ + dicséret 'похвала, хвала'; önkritika 'самокритика' < ön 'само’ + kritika 'критика'. Как видно из примеров, продуктивным является только тип с местоимением ӧn.

\section{5. Сложные существительные, первый компонент которых - причастие}

В указанной функции причастия на -andó / -endö почти не употребляются, а причастия на -t (-tt) - очень редко.

В этой группе композитов выделяются следующие словообразовательные типы:

a) причастие на -ó / -ö уточняет место, указывая на то характерное действие, которое там обычно происходит или когда-то происходило, например: fürdőház ‘купальня’ < fürd-eni ‘купаться’ + ház ‘дом’; hálószoba ‘спальня’ < hál-ni ‘спать’ + szoba 'комната'; szülőfalu ‘родная деревня’ < szül-ni ‘родить' + falu ‘деревня’. Вторым компонентом таких сложных слов является существительное, обозначающее конкретный предмет, например: ház ‘дом', szoba 'комната'. Тип продуктивный;

б) причастие на -ó / -ӧ уточняет орудие, указывая, какое характерное действие им производится, например: írógép 'пишущая машинка' < ír-ni 'писать' + gép 'машина'; kötốtū 'вязальная спица' < köt-ni 'вязать' + tü ‘спица'; öntözőkanna ‘лейка' < öntöz-ni ‘поливать' + kanna ‘бидон'; vetögép ‘сеялка' < vet-ni 'сеять' + gép ‘машина'. Вторым компонентом таких сложных слов часто является существительное gép ‘машина’ или существительное, обозначающее другое орудие производства. Тип продуктивный;

в) причастие на -ó / -ö уточняет предмет или лицо, указывая, какое действие направлено на него, например: töltőtoll 'авторучка' < tölt-eni 'наполнить' + toll 'ручка'; vetömag 'семена, семенной фонд’ < vet-ni 'сеять' + mag ‘семя’. Тип непродуктивный;

г) причастие на -ó / -ӧ уточняет предмет, указывая на его характерное состояние, свойство или действие, например: állóvíz 'стоячая вода' < áll-ni ‘стоять' + víz ‘вода'; csörgökígyó ‘гремучая змея’ < csörög-ni 'греметь' + kígyó ‘змея’; döntőbíróság ‘третейский суд’ < dönt-eni ‘решать’ + bíróság ‘суд’. Тип малопродуктивный;

д) детерминативные композиты, у которых первым компонентом выступает причастие на $-\boldsymbol{t}(-\boldsymbol{t} \boldsymbol{t})$, являются большей частью не идиоматичными и поэтому в зависимости от ударения выступают как сложные слова или синтаксические словосочетания, например: forraltvíz или forral tvíz ‘кипяченая вода'; töröttbors или törött bors ‘молотый перец’; sültcsirke или sült csirke ‘жареный цыпленок’.

Другие словообразовательные типы, входящие в данную группу, являются малораспространенными.

\section{6. Сложные существительные, первый компонент которых - наречие}

У этой группы сложных существительных первым компонентом в основном выступают слова, внешне напоминающие падежные формы существительного, от которых они, однако, полностью оторвались по значению. В большинстве эти композиты происходят от сложных глаголов или от сочетания глаголов с наречиями, например: félrelépés 'супружеская неверность' < félre ‘в сторону' + lépés 'шаг, поступок'; szemrehányás 'упрек’ < szemre ‘на глаз' + hányás ‘бросание, кидание, швыряние’; éhenhalás 'голодная смерть’ < éhenhalni ‘умереть/умирать с голоду’.

\section{Заключение}

Таким образом, образование сложных существительных на основе подчинительной связи - это продуктивный способ словообразования. Сложные существительные подчинительного типа, представленные в словаре “Magyar-orosz szótár = Венгерско-русский словарь”, разнообразны по структуре, семантике и употреблению. 
Согласно результатам проведенного исследования, мы пришли к выводу, что для сложных существительных подчинительного типа в венгерском языке имеется несколько моделей (существительное + существительное, прилагательное + существительное, числительное + существительное, местоимение + существительное, причестие + существительное, наречие + существительное). Наиболее продуктивными в венгерском языке на данный момент являются модели «существительное + существительное», «прилагательное + существительное», по которым образуются слова различной семантики, тематики, применения.

Исследование сложных существительных подчинительного типа в венгерском языке может быть продолжено, перспективным направлением будут сравнительно-сопоставительные исследования в финно-угорских языках.

\section{Источники | References}

1. Балашша Й. Венгерский язык. М.: Изд-во иностранной литературы, 1951.

2. Василевская Е. А. Словосложение в русском языке: очерки и наблюдения. М., 1962.

3. Грамматика русского языка: в 2-х т. / под ред. В. В. Виноградова, Е. С. Истриной, С. Г. Бархударова. M., 1960. T. 1.

4. Грамматика современного русского литературного языка / отв. ред. Н. Ю. Шведова. М., 1970.

5. Майтинская К. Е. Венгерский язык. Грамматическое словообразование: в 3-х ч. М.: Изд-во АН СССР, 1959. Ч. 2.

6. Науменко-Папп А. Практический курс венгерского языка. М.: Высшая школа, 1982.

7. A. Jászó A. A magyar nyelv könyve. Budapest: Trezor Kiadó, 2007.

8. Gáldi L., Uzonyi P. Magyar-orosz szótár = Венгерско-русский словарь. Budapest: Akadémia Kiadó, 2000.

9. Hegedûs R. Magyar nyelvtan: formák, funkciók, összefüggések. Budapest: Tinta könyvkiadó, 2004.

10. Kiss É., Kiefer F., Siptár P. Új magyar nyelvtan. Budapest: Osiris Kiadó, 2003.

11. Korchmáros Valéria M. Lépésenként magyarul. Magyar nyelvtani kézikönyv. Szeged: Jatepess, 2006.

12. Magyar grammatika / szerk B. Keszler. Budapest: Műszaki Könyvkiadó, 2017.

\section{Информация об авторах | Author information}

RU Арискина Татьяна Павловна ${ }^{1}$, к. филол. н.

${ }^{1}$ Мордовский государственный университет им. Н. П. Огарёва, г. Саранск

EN Ariskina Tatyana Pavlovna ${ }^{1}, \mathrm{PhD}$

${ }^{1}$ Ogarev Mordovia State University, Saransk

$\overline{1}$ ariskina82@mail.ru

\section{Информация о статье | About this article}

Дата поступления рукописи (received): 15.10.2021; опубликовано (published): 30.11.2021.

Ключевые слова (keywords): сложное слово; имя существительное; подчинительная связь; словообразовательная модель; венгерский язык; compound word; noun; subordinate relationship; word-formation model; Hungarian language. 